\title{
A clinical study of the EMI scanner: implications for provision of neuroradiological services
}

\author{
J R BARTLETT, G NEIL-DWYER
}

British Medical fournal, 1978, 2, 813-815

\section{Summary and conclusions}

The records of the first $\mathbf{5 7 1}$ patients to be examined with an EMI brain scanner were assessed. The patients were divided into diagnostic categories according to their clinical presentation. The intracranial investigations that would have been performed had the scanner not been available were compared with the investigations that were actually performed. As expected, the number of contrast investigations fell, but the reduction surpassed expectation.

If the full clinical impact of the scanner is to be realised the patient's illness must be defined in detail and strict attention paid to radiographic detail. By reducing the number of special contrast investigations use of the scanner enables existing contrast facilities to serve a wider population; and use of the brain scanner in district general hospitals would improve the service to patients, especially those with head injuries.

\section{Introduction}

In February 1976 an EMI computerised axial tomography (CAT) brain scanner was installed at the Brook General Hospital, which presented a unique opportunity to study the clinical usefulness of the scanner in a busy general neurosurgical unit. For the first 10 months of the machine's use there was no consultant neuroradiologist, so most of the conventional contrast neuroradiology was carried out by members of the neurosurgical team. The shortage of specialist radiological skills ensured that only those angiograms, air encephalograms, and ventriculograms that were absolutely necessary were carried out. We therefore analysed the reduction in the number of contrast in vestigations that was made possible by the use of the scanner.

\section{Patients and methods}

The records of patients admitted to the neurosurgical unit from 14 February 1976 to 13 February 1977 were examined. Of the 5.71 patients examined a few were excluded because the examination was performed for instruction in the use and value of the scanner. A clinical diagnosis was made in the remaining patients on the basis of history, examination, and plain radiography. The patients were

Brook General Hospital, London SE18

J R BARTLETT, FRCS, consultant neurosurgeon

G NEIL-DWYER, FRCS, consultant neurosurgeon

divided into groups according to their clinical diagnosis: intracranial tumour; vascular disease; head injuries; intracranial infection; degenerative disease; congenital abnormalities; and miscellaneous conditions, including orbital tumours.

A few patients whose conditions did not justify angiography, air studies, or, in the case of head injuries, an exploratory operation were excluded. The remaining cases were investigated. In some cases the diagnosis was revised after the scan and the revised category was used in the analysis.

The number of contrast radiological procedures that would have been carried out on each patient if there had not been a scanner was estimated. To exclude the possibility that the estimated number of investigations was too high we compared the estimate with the figures recorded for 1975 and 1974 . The estimated 1.567 contrast investigations per person compared well with the 1.504 performed in 1975 and the 1.677 performed in 1974

The analysis consisted in comparing the estimated number of investigations without a scanner with the number actually performed.

\section{ANALYSIS}

For each diagnostic category there were two sets of scans: positive and negative. The two sets were analysed separately.

We considered that if the scanner determined only those patients who required investigation there would be no reduction in the number of radiological tests performed in the group of patients with positive scans. A significant reduction in the number of angiograms and air studies would, however, indicate that patients were being treated on the basis of the scan findings. Two further important questions that we hoped the analysis would answer were: firstly, if an additional investigation was carried out did the finding affect treatment?; secondly, if an additional test was not performed was there any detriment to the patient on that account and, if so, what ?

\section{Results}

Table I compares the number of special investigations estimated to be required without a CAT scanner and the number actually performed. In all diagnostic categories there was a reduction in the number of investigations performed, particularly for tumours, head injuries, infection, and degenerative disease. Table II shows percentage reductions in contrast radiology, correlating the reason for investigation and positive and negative (normal) scan findings. The reduction in the number of contrast investigations performed occurred with both negative and positive scans. Table III shows the percentage reduction of special tests and exploratory burr holes correlated with the scan findings.

There were only five cases in which clinical factors led us to perform further investigations because of failure to interpret the scan correctly.

Case 1 -The scan on one patient with an invasive meningioma was interpreted as showing a glioma, and the patient underwent a burr hole biopsy, which showed oedematous brain. The carotid angiogram showed the "en plaque" meningioma that was visible on the original enhanced scan.

Case 2-A recurrent acoustic neuroma was not seen because no contrast enhancement was used. The recurrent tumour had grown to occupy the space left after the removal of the lateral third of the cerebellar hemisphere, so that the fourth ventricle was not displaced. 
Case 3-In one case the CAT scan failed to show a colloid cyst of the third ventricle, which was subsequently shown on an air encephalogram. The scans were reviewed and the cut that would have shown the region of the foramen of Munro was missing.

Case 4-The CAT scans of a patient who had a cerebellar haemangioblastoma were marred by motion artefact. This patient was submitted to an air study that failed to fill the fourth ventricle. The repeat scan confirmed the presence of a tumour.

Case 5-In another case a small meningioma adjacent to the petrous bone was not recognised. The subsequent angiogram showed massive swelling of the temporal lobe, which was interpreted as a glioma until operation showed a meningioma. When the scan was reviewed the lesion was clearly visible; it had been missed because the head had not been placed in perfect axial alignment in the scanner.

TABLE I-Comparison between number of special investigations performed in group of patients if there had not been a scanner (estimated) and number actually performed

\begin{tabular}{|c|c|c|c|c|c|c|}
\hline & \multicolumn{3}{|c|}{ Estimated investigations in: } & \multicolumn{3}{|c|}{ Actual investigations in: } \\
\hline & $\begin{array}{l}\text { Patients } \\
\text { with } \\
\text { positive } \\
\text { scans }\end{array}$ & $\begin{array}{l}\text { Patients } \\
\text { with } \\
\text { negative } \\
\text { scans }\end{array}$ & Total & $\begin{array}{l}\text { Patients } \\
\text { with } \\
\text { positive } \\
\text { scans }\end{array}$ & $\begin{array}{c}\text { Patients } \\
\text { with } \\
\text { negative } \\
\text { scans }\end{array}$ & Total \\
\hline Tumours $\ldots$ & 163 & 65 & 228 & 23 & 9 & 32 \\
\hline $\begin{array}{ll}\text { only) }_{\text {Head injuries }} & \cdots \\
\text { Infection } & \cdots \\
\text { Degenerative } & \end{array}$ & $\begin{array}{r}181 \\
128 \\
45\end{array}$ & $\begin{array}{r}104 \\
43 \\
13\end{array}$ & $\begin{array}{r}285 \\
171 \\
58\end{array}$ & $\begin{array}{r}103 \\
7 \\
6\end{array}$ & $\begin{array}{r}95 \\
1 \\
0\end{array}$ & $\begin{array}{r}198 \\
8 \\
6\end{array}$ \\
\hline \begin{tabular}{ll}
\multicolumn{1}{c}{ disease } & $\ldots$ \\
Congenital & $\ldots$ \\
Miscellaneous &..
\end{tabular} & $\begin{array}{l}62 \\
14 \\
25\end{array}$ & $\begin{array}{r}2 \\
3 \\
12\end{array}$ & $\begin{array}{l}64 \\
17 \\
37\end{array}$ & $\begin{array}{l}5 \\
5 \\
8\end{array}$ & $\begin{array}{l}0 \\
2 \\
2\end{array}$ & $\begin{array}{r}5 \\
7 \\
10\end{array}$ \\
\hline Total & 618 & 242 & 860 & 157 & 109 & 266 \\
\hline
\end{tabular}

TABLE II-Percentage reductions in contrast radiology correlating provisional diagnostic category and scan findings

\begin{tabular}{|c|c|c|c|c|}
\hline \multirow{2}{*}{\multicolumn{2}{|c|}{ Provisional diagnostic category }} & \multicolumn{3}{|c|}{$\%$ Reduction in patients with: } \\
\hline & & Positive scans & Negative scans & Total \\
\hline 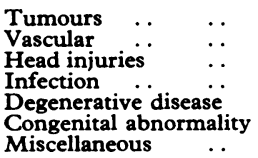 & $\begin{array}{ll}\cdots & \ldots \\
\cdots & \cdots \\
\cdots & \cdots \\
\cdots & \cdots \\
\cdots & \cdots\end{array}$ & $\begin{array}{l}86 \\
43 \\
95 \\
87 \\
92 \\
64 \\
68\end{array}$ & $\begin{array}{r}87 \\
9 \\
98 \\
100 \\
100 \\
33 \\
83\end{array}$ & $\begin{array}{l}86 \\
30 \\
97 \\
90 \\
92 \\
59 \\
73\end{array}$ \\
\hline
\end{tabular}

TABLE III-Percentage reductions in special tests and exploratory burr holes correlated with scan findings

\begin{tabular}{|c|c|c|c|}
\hline \multirow{2}{*}{$\begin{array}{l}\text { Investigation or } \\
\text { procedure }\end{array}$} & \multicolumn{3}{|c|}{$\%$ Reduction in patients with: } \\
\hline & $\begin{array}{l}\text { Positive } \\
\text { scans }\end{array}$ & $\begin{array}{c}\text { Negative } \\
\text { scans }\end{array}$ & $\begin{array}{c}\text { Total } \\
\text { reduction }\end{array}$ \\
\hline $\begin{array}{lll}\text { Angiography } & \ldots & \ldots \\
\text { Air studies } & \ldots & \cdots \\
\text { Isotope brain scans } & \cdots \\
\text { Exploratory burr hole } \\
\text { procedure (head injuries) }\end{array}$ & $\begin{array}{c}69 \\
85 \\
98 \\
\\
\text { Definitive } \\
\text { operations only }\end{array}$ & $\begin{array}{r}37 \\
96 \\
95 \\
100\end{array}$ & $\begin{array}{r}61 \\
90 \\
97 \\
100\end{array}$ \\
\hline
\end{tabular}

\section{Discussion}

As in other neurosurgical units, the introduction of the scanner was followed by a reduction in the volume of contrast neuroradiology. The effect was immediate, has been maintained, and is generally greater than that reported by Thomson. ${ }^{1}$

Our analysis showed clearly the effect that the scanner had on the treatment of patients with positive scans: many were treated on the scan findings alone. For example, tumours were removed, biopsies taken, and abscesses aspirated. The full impact is not completely shown in our tables. Thus there was an $86 \%$ reduction in contrast radiology for tumours, despite the fact that certain patients had several other tests. The examination of the relationship between the findings of a scan and the pattern of subsequent neuroradiological tests helped to highlight the complementary part the scanner plays in relation to conventional radiological tests in planning patient management.

In cerebrovascular disease angiography is the definitive investigation for showing aneurysms, vascular malformations, stenosis, or vascular occlusions. Patients with positive scans underwent fewer contrast radiological procedures than those with negative scans, however, because the CAT scanner often showed changes that, together with the clinical picture, indicated that no neurosurgical operation was either reasonable or feasible. In these patients it was possible to dispense altogether with contrast radiology.

The scanner is not only a diagnostic tool; it is also particularly useful in planning treatment. But sufficient attention has to be paid to incontrovertible data, such as a change in tissue density, alteration in ventricular size, the presence of a mass lesion, and disorganisation of the normally formed structures. Paxton and Ambrose ${ }^{2}$ emphasised that differentiation between tumours, infection, and infarction may not be possible on the scan findings alone. Our experience indicates that this holds true.

As many decisions were based on the scan findings only, there was concern lest the lack of information obtainable from other procedures had adversely affected management. The collection of data and the analysis were designed to answer this question, but in fact there were only five cases in which clinical factors necessitated further investigation that showed the scan to be wrong. Some of these cases, as well as others, showed the importance of attention to radiographic detail to ensure straight pictures, absence of artefact, and a complete examination. Lack of attention to these details demanded repeat examinations in many cases, and, despite vigilance, several patients were submitted to contrast radiology unnecessarily. But in many other cases even poor quality pictures provided enough on which to base a clinical decision.

The CAT scanner has a unique role in the management of patients with head injury. Our experience fully corroborates the observations of others $^{2}{ }^{3}$ on the great accuracy of the CAT diagnosis. No blind emergency burr hole explorations were required, and only one angiogram was performed. This is a definite change for the better in management. By providing knowledge of the nature of the intracranial events to those responsible for the initial care of patients with head injuries $(1.7 \%$ of those admitted to hospital in South-east Thames

TABLE v-Neuroradiological work loads before and after introduction of brain scanner

\begin{tabular}{|c|c|c|c|c|c|c|c|c|c|c|c|}
\hline & & & & & \multicolumn{3}{|c|}{ Investigations performed in $1974^{*}$} & \multicolumn{2}{|c|}{ Introduction of scanner } & \multirow{2}{*}{$\begin{array}{c}\text { Maximum No } \\
\text { of } \\
\text { investigations } \\
\text { possible } \\
\text { per room } \dagger\end{array}$} & \multirow{2}{*}{ Utilisation } \\
\hline & & & & & $\underset{\substack{\text { For } \\
\text { neurosurgical } \\
\text { unit }}}{ }$ & $\begin{array}{c}\text { For } \\
\text { neurological } \\
\text { unit }\end{array}$ & Total & $\begin{array}{c}\text { No of } \\
\text { tests } \\
\text { needed }\end{array}$ & $\begin{array}{c}\% \\
\text { Reduction }\end{array}$ & & \\
\hline $\begin{array}{l}\text { Bilateral carotid angiogram } \\
\text { Single side angiogram } \\
\text { Vertebral angiogram } \\
\text { Air encephalogram } \\
\text { Ventriculogram }\end{array}$ & $\begin{array}{l}\cdots \\
\because \\
\therefore\end{array}$ & $\begin{array}{l}\ldots \\
\cdots \\
\cdots \\
\cdots\end{array}$ & $\begin{array}{l}\because \\
\because \\
\cdots \\
\cdots\end{array}$ & $\begin{array}{l}\ldots \\
\because \\
\because \\
\therefore\end{array}$ & $\begin{array}{r}125 \\
221 \\
32 \\
57 \\
9\end{array}$ & $\begin{array}{r}26 \\
311 \\
9 \\
194 \\
0\end{array}$ & $\begin{array}{l}875 \\
260\end{array}$ & $\begin{array}{r}437 \\
26\end{array}$ & $\begin{array}{l}50 \\
90\end{array}$ & $\begin{array}{r}1500 \\
750\end{array}$ & $\begin{array}{l}29 \\
3.5\end{array}$ \\
\hline
\end{tabular}

*Catchment populations for neurosurgery and neuroradiology were 2024240 and 1144120 respectively. (Hospital Activity Analysis, 1974.) 
region in 1974) the scanner could remove the fear that a treatable lesion may be missed or recognised too late.

This is of particular interest at a time when high-cost technology medicine requires justification. Fineberg et al $^{4}$ proposed standards by which a new piece of medical technology should be judged, and his criteria have been developed and adopted by the American Medical Association for its policy on CAT scanning. There are five levels of efficiency: (a) technical capability, whether the apparatus provides an accurate representation of the area scanned; (b) diagnostic accuracy, whether it provides information that contributes to a correct diagnosis (c) diagnostic impact, the extent to which CAT scanning replaces other diagnostic procedures; $(d)$ therapeutic impact, the change in management that would not have taken place without information from the scan; and (e) outcome, the effect of CAT scan information on patient morbidity and mortality.

Undoubtedly the scanner satisfies the first three criteria, and in the care of those with head injuries there are good grounds for believing that treatment and outcome in many cases may be largely determined by the scan findings.

\section{ADMINISTRATIVE AND ECONOMIC FACTORS}

Some cost implications may be observed from the analysis of the reduced radiological work load correlated with the catchment population.

Table IV shows the requirements of the special units for contrast radiology in 1974 and the effect that the introduction of a CAT scanner had on the work loads in the specialist rooms. The reductions of $50 \%$ for angiography and $90 \%$ for air studies were taken as minimum, on the basis of this series and other observations. ${ }^{15-7}$ The percentage use was calculated from an estimate of the maximum capacity for each room ${ }^{5}$ and tested against that achieved at Brook General Hospital during 1974.

The spare capacity of the equipment indicates that one neuroradiology department could provide the service for about four million people. Therefore, if the number of departments of neuroradiology could be reduced over several years money would be saved. Some of this money could be spent on placing scanners in general hospitals, where ready access to this tool would improve the local service, particularly in managing patients with head injuries, and also reduce the number of patients who require transfer to the central unit for specialist investigation and treatment.

The debate about high-cost medicine should take into account the level of use, clinical efficiency judged by economic criteria, and the relationships that the technology has to the other aspects of the service. The high cost of a piece of equipment alone does not justify centralisation.

\section{References}

1 Thomson, J L G, Health Trends, 1977, 9, 16

2 Paxton, R, and Ambrose, J, British fournal of Radiology, 1974, 47, 530.

${ }^{3}$ Ambrose, J, Gooding, M R, and Uttley, D, Lancet, 1976, 1, 847.

${ }^{4}$ Fineberg, H V, Bauman, R, and Sosman, M, fournal of the American Medical Association, 1977, 238, 224.

5 Jonesson, E, and Marke, L A, Health Care Management Review, 1977, $2,37$.

6 Wortzman, G, Holgate, R C, and Morgan, P P, Radiology, 1975, 117, 75

${ }^{7}$ Buerger, R E, and Huchman, M, Computed Tomography Survey. Chicago, Illinois, Rush Presbyterian St Luke Medical Centre, 1975.

(Accepted 26 fuly 1978)

\title{
Evaluating cost-effectiveness of diagnostic equipment: the brain scanner case
}

\author{
J R BARTLETT, G NEIL-DWYER, J M M BANHAM， D G CRUICKSHANK
}

British Medical fournal, 1978, 2, 815-820

\section{Summary and conclusions}

An approach to evaluating the cost-effectiveness of hightechnology diagnostic equipment has been devised, using the introduction of computerised axial tomography (CAT) as a model. With the advent of CAT scanning, angiography and air encephalography have a reduced, though important, role in investigating intracranial disease, and the efficient use of conventional equipment requires the centralisation of neuroradiological services, which would result in major cash savings. In contrast, the pattern of demand for CAT scanning, in addition to the acknowledged clinical efficiency of the scanner and its

Brook General Hospital, London SE18

J R BARTLETT, FRCs, consultant neurosurgeon

G NEIL-DWYER, FRCS, consultant neurosurgeon

McKinsey and Co, London

J M M BANHAM, MA, principal

D G CRUICKSHANK, CA (now commercial director, Times Newspapers) unique role in the head-injured patient, ephasises the need for improved access to scanners. In the interest of the patients the pattern of service must change.

\section{Introduction}

The cost of introducing computerised axial tomography (CAT) scanners into a neuroradiological service is high. Justification for this expenditure is particularly important at a time when there is widespread concern at the escalating costs of health care.

There are three aspects to the economic case for any piece of medical equipment : firstly, the effect on existing procedures and equipment-in this case the large reduction in demand for angiograms and encephalograms; secondly, the effect of the new equipment on existing services-a fall in demand for conventional neuroradiology raises the possibility that fewer departments could serve the population; and, finally, the reduction in morbidity and mortality that takes place as a result of introducing the equipment. We show here how all three aspects can be taken into account and describe an approach to evaluating the cost of CAT scanning of the brain that could also be applied to other medical equipment. The analysis consists in (a) assessing the likely demand for brain scanning and other neuroradiological services in an NHS region; $(b)$ identifying 